\title{
Building Scheme for an Ecological Slope Protection System of Three Gorges Reservoir Bank
}

\author{
Guo Yuan-Chen ${ }^{1,2,}$, Wang Xue ${ }^{1}$, Chen Xiang ${ }^{1}$ and Zhu Ming ${ }^{1}$ \\ ${ }^{I}$ College of Civil Engineering, Chongqing Three Gorges University, 780 ShaLong Road, Wanzhou District, \\ Chongqing City, 404100, China \\ ${ }^{2}$ College of Materials Science and Engineering, Chongqing University, No.174, Shazheng street, Shapingba District, \\ Chongqing 400004, China
}

\begin{abstract}
Building an ecological slope protection system in the drawdown area of Three Gorges reservoir bank is imperative. Multiple anti-slide bearings were fixed on the riverside slope of the fluctuating zone of the reservoir area, and antioverturning boards were fixed on the bearings. All the anti-slide bearings, which were placed in the same height position in the transverse direction of the riverside slope, were connected by steel bars to form the backbone slip in the longitudinal direction. Two neighboring backbone slips in the transverse direction formed a groove. In the grooves, fill layer, water layer, fermented silt filling, and soil layer were paved sequentially from bottom to top. The results show that the slope protection system effectively manages the sludge, wastewater, and fluctuating zone treatments as one body; reduces energy consumption; saves energy; and benefits the environment.
\end{abstract}

Keywords: Building scheme, constructed wetland, slope protection system, three Gorges reservoir bank.

\section{INTRODUCTION}

The water level at Three Gorges reservoir ranges between 145 and $175 \mathrm{~m}$ as a result of the adoption of the "store clear water and discharge the sludge" principle $[1,2]$. The water level is high in summer and low in winter; the surface oil is washed away because of periodic inundation and water scouring, which cause landslides and damages to the landscape $[3,4]$. At the same time, a large amount of silt has formed because of the inflow of domestic sewage from cities along the Yangtze River and the precipitation of silt from other rivers $[5,6]$. Thus, building an ecological slope protection system in the drawdown area of Three Gorges reservoir bank is imperative.

This paper focuses on studying the protective effects of the ecological slope protection structure and the treatment of heavy metal pollution by bioremediation technique, as well as their purification effect of constructed wetlands on polluted urban stream water. To form the biological communities in the artificial wetland system, the slope protection panel was made of porous concrete to supply organisms and let the rainwater in. The fertilized substratum was made of fermented silt to adequately provide elements that are essential to the growth of emergent plants and landscape plants. The silt will be applied to agricultural farming after longterm absorption and remediation, thus the earth that will not be used for farming will be returned to nature.

\footnotetext{
*Address correspondence to this author at the College of Civil Engineering, Chongqing Three Gorges University, 780 ShaLong Road, Wanzhou District, Chongqing City, China 404100a; Tel: +8615025576096;
}

Fax:+8623 58102281; E-mail: gyc1982@aliyun.com

\subsection{Construction Ideas}

Artificial wetland ecological slope protection system was composed of a prefabricated permeable panel, fill layer, water layer, fermented silt filling and soil layer. Large aquatic plants were planted in the reserved hole to divide $N(N$ is a natural number except 0 ) grooves into sections.

The permeable panel and transverse anti-slide bearings were made of ecological slope protection composite material. Self-made concentration agent was added to the permeable panel and bearings as a supplement to enhance the two components' mechanical properties and working performance [7]. The permeable panel can effectively resist corrosion and rain erosion, and is beneficial to plant growth. The transverse anti-sliding bearings can not only fix effectively but also increase the decontamination ability of the system. After its fermentation, reservoir silt can be used as the matrix layer of filler. It is of high fertility, making it conducive to the growth of emergent plants, whose roots can, in turn, purify silt. Activated carbon or gravel can purify sewage and absorb harmful elements, such as heavy metals. The above structure constitutes the ecological slope protection structure.

\subsection{Construction Method}

The system consists of the sedimentation tank, drip canal, and structure layer. The structure layer is consisted of fill layer, water layer, fermented silt filling, and surface layer (as can be seen from Fig. 1). The surface layer comprises water plants, soil, slope protection permeable panel (the panel is fixed to the slope by anti-slide bearings, which are connected by a transverse connecting bar). The water layer has a pebble and active carbon layer for the management of the riparian zone of the slope. 


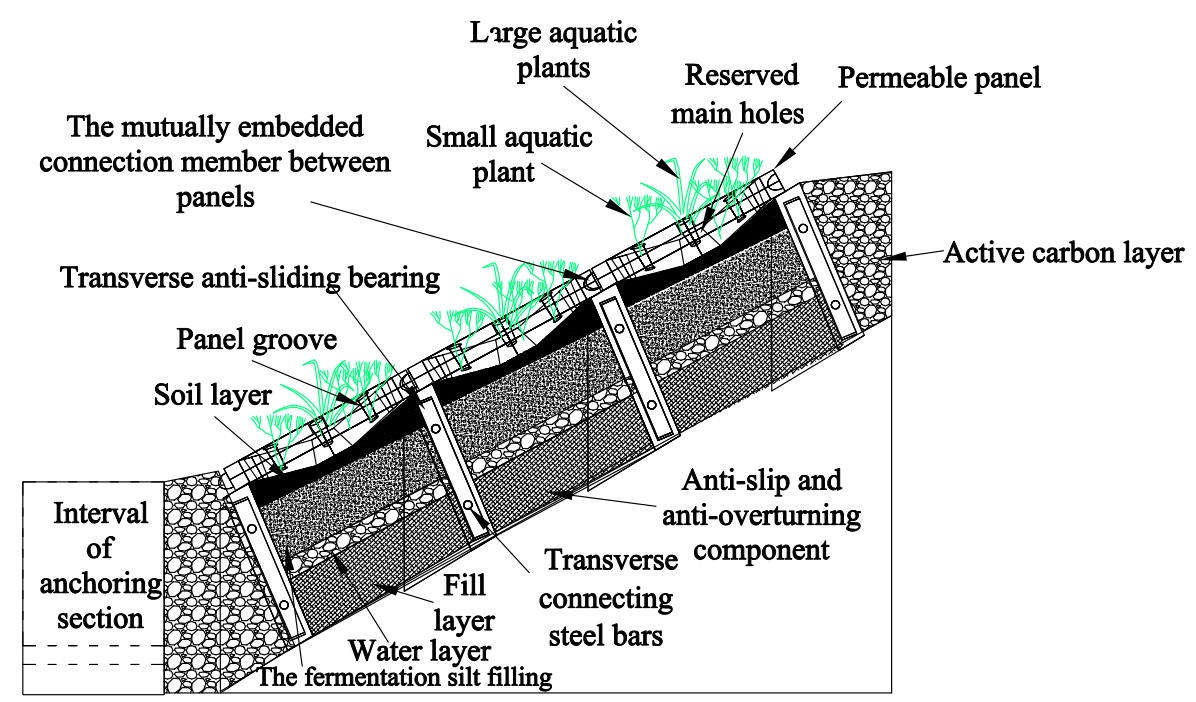

Fig. (1). Schematic diagram of the horizontal subsurface flow wetland ecological slope protection system.

\section{WORKING METHOD OF THE SLOPE PROTEC- TION SYSTEM}

After rough purification in the sedimentation tank, the waste water flows into the drip irrigation-type aqueduct, which allows for the even distribution of water in the areas. The waste water flows across the active carbon layer, where some heavy metals and harmful elements such as $\mathrm{N}$ and $\mathrm{P}$ can be absorbed. The waste water then continues its way to the horizontal subsurface flow wetland. The downward waste water flows at a low rate through a layer of active carbons (or gravels) between the upper silt layer and the lower silt layer then through the roots of plants, whose growth depends heavily on such elements as N, P, K, and heavy metals. In addition, transverse bearings which are made of permeable materials and are utilized to prevent silts from flowing along with the water. Thus the water can be purified from one layer to another before the water flows into the Yangtze River. In this case, the water can be discharged up to the standards. The heavy metals in the silt can also be restored up to the standards in a year or two and can be recycled on the basis of regular desisting.

\section{SIMULATION SYSTEM AND EFFECT EVALUA- TION}

To verify the effect of constructed wetland ecological slope protection system, a small simulation system was built on the bank of the Three Gorges reservoir drawdown area according to the slope protection structure design. The following construction scheme was adopted:

(1) The permeable panel was manufactured according to the optimal formula for water permeable brick and selfmade concentration agent.

(2) The riparian zone was repaired and cleaned when the water level was low, and then tamped.

(3) The drip water channel was constructed based on the $175 \mathrm{~m}$ water level. Its cross section was $500 \mathrm{~mm} \times 500$ $\mathrm{mm}$ in dimension.

(4) Anti-slide bearings were fixed into the soil about $50 \mathrm{~mm}$ deep. Slope distance was $420 / \cos \alpha \mathrm{mm}$, where $\alpha$ is the slope angle. Anti-slide bearings were connected by steel bar in the transverse direction.

(5) The first silt layer was paved on the slope and had been compacted or wiped with cement mortar. Its thickness was $100 \mathrm{~mm}$. The layer was then compacted slightly.

(6) Water supply pipes were paved on the structure layer, which was paved with silt had poor permeability. Horizontal and vertical intervals of the network were based on permeability. For example, for $4000 \mathrm{~mm} \times 4000 \mathrm{~mm}$, one or two holes were made as water supply point in each pipe section.

(7) A $40 \mathrm{~mm}$ active carbon layer was paved to isolate the water supply pipes from the silt. Active carbon was used to wrap the hole.

(8) The second silt layer was paved on the active carbon structure layer. It had a thickness of $150 \mathrm{~mm}$. Then, this layer was slightly compacted.

(9) Natural soil layer was paved on the second silt layer and then compacted slightly. The thickness of the natural soil layer was $40 \mathrm{~mm}$.

(10) Highly permeable panel was laid on the natural soil layer. Two adjacent blocks should be both embedded as a whole.

(11) Some amount of soil was added into the permeable panel depression to make the soil surface and the panel supreme in the same plane. Some seeds of small plants such as Cynodon dactylon were buried into the soil. Large aquatic plants such as Typha latifolia were planted in the reserved holes.

The plants had grown very well four months after the simulation system was constructed.

Some samples were taken from the domestic sewage system and allowed to flow into the simulation system, and were tested again at the terminal of the system. The author found that the municipal wastewater treated in such a way meets the level III water quality standards set in the Environmental Quality Standard for Surface Water (GB 38382002) and can be freely discharged into the Yangtze River. 


\section{CONCLUSION}

With the proposed ecological slope protection system, heavy metals and organics that pollute the water are absorbed by plants. Contaminants are transferred, received, and transformed by plants, thus purifying the water and cleaning the environment.

Currently, sewage of some cities along the Yangtze River flow into the river after a simplified process, which results in the serious pollution of the Yangtze River. The proposed system can be used as a final barrier to process sewage and the source of silt. It is environment-friendly and can thus tremendously benefit the society. Thus, the proposed structure and the construction scheme are worthy of promotion and adoption.

\section{CONFLICT OF INTEREST}

The authors confirm that this article content has no conflict of interest.

\section{ACKNOWLEDGEMENTS}

This project was supported by the Project of National Natural Science Foundation of China (51202304), Natural Science Foundation Project of CQ CSTC (cstc2012jjA 50005), Project funded by China Postdoctoral Science Foundation (2014M552320) and Scientific, Technological Talents' Special Funds of Wanzhou District and Scientific and Technological Research Program of Chongqing Municipal
Education Commission (KJ1401016), Youth Project of Chongqing Three Gorges College (13QN-20).

\section{REFERENCES}

[1] L. Cao, F.Y. Ji, M. Lin, S. Li and T.J. Wang, "Soil phosphorous form analysis in fluctuating zone of three gorges reservoir area", Resources and Environment in the Yangtze Basin, vol. 20, no.1, pp.101-105, January 2011.

[2] J.J. Zhang, R.R. Ren, J.Z. Zhu, C. Song, J. Liu, J. Fu, H. Hu, J. Wang, H. Li, and J. Xu, "Preliminary experimentation on flooding resistance of mulberry trees along the water-fluctuation belt of the Three gorges reservoior", Scientia Silvae Sinicae, vol. 48, no. 5, pp. 154-158, May 2012.

[3] C.H. Liu, C.X. Chen, X.T. Feng and G.F. Xiao, "Effect of groundwater on stability of slopes at reservoir bank", Rock and Soil Mechanics, vol. 26, no. 3, pp. 419-422, March 2005.

[4] J. G. Bai, and Q. Xu, "Study on model of evolution of band collapse in the three goges", Journal of Inner Mongolia Agricultural University, vol. 29, no. 3, pp. 108-111, March 2008.

[5] Y. Xu, P. Zang, C.X. Jia, B. Liu, X. Wei and R.H. Yuan, "Discharge Characteristic of the Rural Domestic Wastewater and Its Influencing Factorsin the Three Gorges Reservoir Region of Chongqing", Journal of Agro-Environment Science, vol. 29, no. 4, pp. 758-763, April 2009

[6] Y.L. Cao, C.M. Li and P. Que, "Evaluating and clustering analysis of non-pointsource pollution in Three Gorges Reservoir Region", Journal of Agro-environment, vol. 268, no. 632, pp. 857-862, March 2007.

[7] Y.C. Guo, B. Xie, H.D. Wang, T. Dong, Y. Li, J. Tian, and C. Hu, "Experimental study on the preparation of permeable crystallization type concentrating agent making use of recycled concrete micropowder", International Journal of Earth Sciences and Engineering, vol. 6, no. 1, pp. 153-157, January 2013.

Received: February 02, 2015

Revised: March 31,2015

Accepted: March 31, 2015

(C) Yuan-Chen et al.; Licensee Bentham Open.

This is an open access article licensed under the terms of the Creative Commons Attribution Non-Commercial License (http://creativecommons.org/licenses/ by-nc/3.0/) which permits unrestricted, non-commercial use, distribution and reproduction in any medium, provided the work is properly cited. 